\title{
Mimicry: Towards a semiotic understanding of nature
}

\author{
Timo Maran \\ Department of Semiotics, University of Tartu, \\ Tiigi 78, 50410 Tartu, Estonia \\ e-mail: timo_m@ut.ee
}

\begin{abstract}
Mimicry has been an important topic for biology since the rise of the Darwinian theory of evolution. However, by its very nature mimicry is a sign process and the quest for understanding mimicry in biology has intrinsically always been a semiotic quest. In this paper various theories since Henry $\mathrm{W}$. Bates will be examined to show how the concept of mimicry has been shifted from perceptual resemblance to a particular communicative structure. A concept of mimicry will then be formulated which emphasizes its dynamic properties, and finally, mimicry will be considered in the framework of ecosemiotics.
\end{abstract}

In 1861, after returning from his eleventh year of study in the Amazon valley, the British entomologist Henry William Bates was the first to discuss the phenomenon of mimicry in a paper addressed to the Linnean Society (Bates 1862). Bates observed that certain similarities between the butterfly species of the two different families of the Heliconidae and the Pieridae might be due to a coevolution of palatable and unpalatable species under variation and natural selection. As a perfect example for the Darwinian theory of evolution, this hypothesis became well-known, and the phenomenon of mimicry has been a "hot topic" in biology ever since.

${ }^{1}$ Bates's paper was published three years after Darwin's Origin of Species, i.e., in the middle of the heated debate about the theory of natural selection. Later, in The Descent of Man, and Selection in Relation to Sex, Darwin adopted Bates's hypotheses in his own argumentation (Darwin 1874: 278-280). Because of the intellectual atmosphere of the time, mimicry was hereafter mostly described in the frame of Darwinian 
Bates's hypothesis was soon checked and further elaborated by naturalists such as Wallace (1870) and Müller (1878), who were both in correspondence with Charles Darwin. Further pioneers in the study of mimicry are Peckham (1889), Poulton (1890) and Shelford (1902, 1912). Important later studies include Heikertinger's (1933, 1954) critique of the Darwinian account of mimicry and the studies of mimicry and camouflage in the frame of ethology (e.g., Blest 1957; Ruiter 1952, 1958; Tinbergen 1960). Other highly relevant contributions to the topic are the evolutional studies by Browers and their school (e.g., Brower 1960; Brower \& Brower 1962, 1964; Brower ed. 1988). The communicational aspects of mimicry were further emphasized in the studies by Wickler (1965, 1968), Vane-Wright (1976, 1980), Pasteur (1982), and Howse \& Allen (1994). During the last decades, the theory of mimicry has been extended in several directions. Among the more recent topics are: polymorphism of mimicries (Mallet \& Gilbert 1995; Winhard 1996; Joron \& Mallet 1998), influences of predator behavior (Bowers et al. 1985; Turner \& Speed 1996; Uesugi 1996), community structure (Burd 1994) and mimicry in plants (Wiens 1978; Johnson 1994; Roy \& Widmer 1999). According to estimates by Wickler (1968: 13) more than three decades ago, the number of papers arguing for or against the concept of mimicry was about 1,500. Today, this number probably exceeds $2,000 .^{2}$

In several papers, Sebeok has argued that biological mimicry should quite naturally belong to the field of semiotics (Sebeok 1979: 116; 1986: 77; 1990: 96-97). Meanwhile, a note about mimicry can be found in all major semiotic textbooks (Ford 1989: 552-553; Nöth 1990: 163; 2000: 269). The topic is mostly discussed as an example of iconicity in animal communication.

This paper develops the argument that mimicry by its very nature is a sign process and that the quest for understanding mimicry in biology has always been a semiotic quest, even if no explicitly semiotic terminology was used. Various theories since Bates will be examined to show how the concept of mimicry has been shifted from perceptual resemblance to a particular communicative function. An outline of mimicry will then be given which emphasizes its dynamic properties,

theory, and for decades it became almost conventional to quote to Darwin in any paper on mimicry.

${ }^{2}$ My estimation does not include papers concerning molecular mimicry (cf. Damian 1963). There has been a considerable increase in the study of imitations between viruses and macromolecular tissue structures. 
and finally, mimicry will be considered in the framework of ecosemiotics. $^{3}$

\section{Mimicry as imitative resemblance}

Similarities between different objects in the natural world have inspired humans throughout the history of culture. Guthrie interprets the principle of cognitive analogy as one of the main causes of animistic religions and as the root of anthropomorphic descriptions of nature in general (1993: 43-47). The Middle Ages and Renaissance were highly inspired by the phenomenon of analogies between nature and culture. Nöth (1998: 335), e.g., describes the Renaissance doctrine of signatures which postulated that the world was perfused with significant homologies between various domains of nature, such as minerals, plants, or the lines of the human body. According to Paracelsius, such iconic signs of natural similarity in nature were believed to be indexical traces of divine sign emitters (signatores). For iconicity in early ethnic art, see Voigt (1986).

Bates and other 19th century naturalists focussed on the immediately visible similarities between organisms of different descendent. According to Bates's definition, the basis of mimicry is visible "resemblance in external appearance, shapes and colors between members of widely distinct families" (Bates 1862: 502). Other definitions of mimicry are based on visual criteria, such as "imitative resemblance", "deceptive resemblance", "mimetic resemblance", or "mimetic analogy" (Bates 1862). Similar notions have been used by Wickler, who emphasized that the term "pattern", or more specifically, "warning pattern", "camouflage pattern", and "protective pattern" had been commonly used in the description of mimicry. Similarities based on other senses were usually excluded from the study of mimicry (Wickler 1968: 8). Wallace went so far as to claim that mimicry according to Bates was restricted to forms of resemblance between animals (cf. Pasteur 1982: 171).

However, in several early field studies (Atkinson 1888; Shelford 1902) the concept of mimicry was first based on the naturalists' experience of surprising analogies between animals in their natural environment, and these early concepts of mimicry were attempts at giving

\footnotetext{
${ }^{3}$ For preliminary notes concerning the classification of mimicry and further semiotic aspects of mimicry, see Maran (1999).
} 
causal explanations of these similarities. ${ }^{4}$ As a comment to Bates's discovery, Darwin wrote: "It had previously been observed that certain butterflies in S. America belonging to quite distinct families, resembled the Heliconidae so closely in every stripe and shade of colour, that they could not be distinguished save by experienced entomologist" (1874: 278).

The definition of mimicry on the basis of the criterion of perceptual similarity has been adopted in standard textbooks of biology. According to The Oxford Companion to Animal Behavior, e.g., mimicry is "the resemblance of one animal (the mimic) to another animal (the model) such, that the two animals are confused" (Malcolm 1987: 387). However this definition leads to empirical problems because it fails to specify the role of the perceiver as the agent in natural selection. ${ }^{5}$ Can the similarities perceived by human minds serve as the empirical basis to determine mimicry? Must not also discrimination errors of predators be taken into account? Furthermore, the resemblance between different biological organisms may have other reasons. Even when we eliminate similarities attributed to the organisms only by human observers, still other evolutionary causes of resemblance between different species must be taken into consideration: evolutionary convergence, physio-morphological or the so-called orthogenetic limitations (cf. Eimer 1897), and even actual phylogenetic proximity. ${ }^{6}$ It is rather questionable to assume mimicry between closely related species, as

\footnotetext{
${ }^{4}$ Among the naturalists who did not account for mimicry in terms of causality was Francé (1908), who defended the extreme position that most forms of resemblance in nature, however functionless they may be, constitute mimicry, including, e.g., seaanemones mimicking plants and spurges (Euphorbiaceae) mimicking cacti. Thayer (1909) stated that all patterns and colours of all animals which prey or are preyed upon are obliterative under certain circumstances. His example, red flamingos, which are supposedly concealed against a red sunset sky, has became well-known as an example of over-interpretation (Thayer 1909).

${ }^{5}$ In my opinion, one of the reasons for the neglect of the important role of the receiver as the actual agent of selection was a too abstract interpretation of Darwin's theory of natural selection.

${ }^{6}$ However, some serious attempts were made to distinguish mimicry from another forms of similarity. Wallace provided five criteria to define mimicry: (1) the imitative species lives in the same area and shares its environment with the imitated; (2) the imitators are always less defended than those who are imitated; (3) the imitators are always less numerous in groups; (4) the imitators differ from the bulk of their allies; (5) the imitation, however minute, is always external and only visual, never extending to internal characteristics or to features that do not affect the external appearance (cf. Poulton 1890). One can notice that none of these criteria are based on actual communicative relationships between imitators and perceivers of the resemblance. Wickler (1968: 46-48) has shown that there are still other cases of mimicry.
} 
Gingerich (1975), e.g., does when he considers the aardwolf Proteles as a mimic whose model is supposed to be the striped hyena Hyaena hyena. Even resemblances between evolutionarily quite distinct species may have not have their cause in mimicry, but in convergence, i.e., in an evolution under similar environmental conditions. For instance, morphological similarities between the eels Anguillidae and the sea snakes Hydrophiidae have most probably been developed because of evolutionary convergence.

\section{Mimicry as threefold communication}

Although there have been descriptions of the reactions of predators in face of their prey animals, including aposematic prey and mimics, since the end of 19th century (Poulton 1887; Finn 1897), a thorough analysis of the perceiver's role in deceptive resemblance only began with studies in the framework of ethology. The long break in the continuity of research was partly due to the progress of Mendelian genetics and the recession of the classical Darwinism (Bowler 1983: 214). Since the 1920's, the interest in the study of protective adaptation including animal coloration and mimicry decreased rapidly. ${ }^{7}$

In the late 1930's and 1940's, the Lorenz-Tinbergen school of ethology created new research interest in the field. Comparative research in animal behaviour brought new insights into mimicry because of its studies in the learning abilities and search behaviour of predators. The concept of the searching image popularized by Tinbergen (1960), which accounted for the properties remembered by the predator in his search for the prey became especially useful. Although this concept is usually attributed to Tinbergen, it was actually first proposed by Jakob von Uexküll (cf. 1957: 62-64). ${ }^{8}$

The first who systematically included the perceiver in his account of protective resemblance was Wickler (1965: 519), who introduced the concept of signal receiver and distinguished different types of perceivers. At the time, it became clear that mimicry is not always exclusively directed against possible predators. Instead, there is a wide va-

${ }^{7}$ A reason for the diminished interest in mimicry may also be doubts expressed as to its adaptational value. As a result of his study of 237,399 prey identifications from 80,000 bird stomachs of more than 300 bird species, L. McAtee stated that there is no correlation whatsoever between protective resemblance and occurrence of the species in the predators diet (Malcolm 1990: 57).

${ }^{8}$ For the influence of Uexküll's works on ethology see Brier (2001). 
riety of different mimicry functions, in particular, aggressive, reproductive, intraspecific, i.e., social mimicry (ibid.; see also Pasteur 1982). ${ }^{9}$ Wickler developed the theory of the mimicry system as a triadic structure of three participants in co-evolution: the mimic, the imitating organism or constructed agent, the model, the (animate or inanimate) entity being imitated, and the signal receiver or operator, the organism that fails to discriminate between model and mimic. ${ }^{10}$ Despite certain similarities with semiotic concepts, Wickler made no reference to semiotics and probably derived his terminology from the behaviourist tradition of ethology. ${ }^{11}$ Another renewal adapted by Wickler, was the use of "mimicry system" instead of "mimicry", indicating so the complex nature of the phenomena:

One condition of mimicry is the existence of two different signal transmitters, $S_{1}$ and $S_{2}$, which transmit the same signal and have at least one signalreceiver, $E$, in common which reacts similarly to both. One signal-transmitter is called the model and the other the mimic, the entire set-up being a mimicry system. (Wickler 1968: 239) ${ }^{12}$

By using plus and minus signs to indicate whether the mimicry situation is advantageous or disadvantageous to the participants, Wickler formalizes mimicry systems and other biological communication structures by means of formulas. For instance, $S_{1}+E-+S_{2}$ describes Bates's protective mimicry: a palatable species $S_{2}$ profits as a mimic from a situation in which it is mistaken by the predator for the less palatable one, the model $S_{l}$. In similar manner, Müller's protective mimicry, i.e., according to which unpalatable species converge in evolution by sharing more similarities in their warning coloration so that the signal receiver learns specific color patterns more quickly, is transcribed by the formula $S_{1}++E++S_{2}$. As one may notice, Müller's mimicry is beneficial to every participant. No agent is deceived and

\footnotetext{
${ }^{9}$ The conceptual distinction between protective (Batesian) and aggressive mimicry - in which the mimic itself is a predator mimicking object or organism harmless to its prey — was made already by Poulton (1890).

${ }^{10}$ Although one may find some similarities between Wickler's threefold mimicry systems and Morris's three dimensions of semiotics, I would caution against any superficial equation. Even if the positions of the "signal receiver" and the "sign interpreter" are alike, it would not be adequate to match the "sign vehicle" or "designatum" with the "model" and "mimic".

${ }^{11}$ For parallels between Wickler's advantage patterns of mimicry and Odum's six basic types of ecological interaction between species see Vane-Wright (1976: 51) .

${ }^{12}$ Wickler (1965) used $S$ instead of $E$ to mark the signal to a receiver.
} 
therefore it is usually no longer considered to be mimicry (Wickler 1968; Wiens 1978; Pasteur 1982).

Wickler's triadic concept of mimicry was developed further by Vane-Wright (1976), who used the affiliations of mimicry agents as his basis of classification. The author distinguishes between disjunct, conjunct and bipolar mimicry systems. In a disjunct system, all protagonists belong to the different species, in a conjunct system all three belong to the same species, and in a bipolar system two species are in interaction. Utilizing Wickler's patterns of advantages as a further element of classification, Vane-Wright distinguishes forty types of possible mimicry systems. His model was improved by Pasteur (1982) who classifies different mimicry systems in case studies. Pasteur distinguishes 18 types of mimicry, 2 types of mimesis, as well as the cases of eucrypsis (homocromy) and nondeceitful homotypy.

In a much debated paper, Vane-Wright (1980) characterizes mimicry systems further by differentiating between mimicry and crypsis on the basis of the signal receiver's experience. ${ }^{13}$ According to his definition, whenever the mimic resembles an organism that belongs to a general "cognitive model" of the signal receiver, there is mimicry (ibid.: 2-3). In crypsis, by contrast, the animal tries to avoid producing signals that might be detected by the signal receiver. Hence, VaneWright define crypsis as a "nonsignal" and place it between the actual communication of signals and situations in which animals avoid producing any signal at all, e.g., by trying hide.

The difference between mimicry and crypsis becomes even clearer when we consider Uexküll's concept of Umwelt. When the model of resemblance plays an important part in the receiver's Umwelt, there is mimicry, but when the mimic tries to dislocate its perceivable properties to a world outside of the receiver's Umwelt by resembling some object that does not belong to this receiver's Umwelt, thus making its message meaningless to the signal receiver, there is crypsis (Maran 2000: 57-59).

With the signal receiver as the third participant in mimicry, the analysis of mimicry emphasizes its systemic properties. The diversity of mimicry gives empirical evidence that features of mimicry develop from all three participants and their specific interplay. Hence, the triadic model of mimicry is a good theoretical basis for observing mimicry signals not directly accessible to human perception. Pasteur has criticized research in mimicry for focussing too much on visual sys-

${ }^{13}$ For further discussions, see Robinson (1981) and Cloudsley-Thompson (1981). 
tems and for showing too little interest in signals that remain invisible to humans (1982: 173-175). Nevertheless, there have been studies of extensions of mimicry beyond the visual in recent years: e.g., chemical mimicry of parasitic ants (Lenoir et al. 1997) and of fungi (Roy \& Raguso 1997; Raguso \& Roy 1998), tactile mimicry of spiders (Jackson \& Wilcox 1993), reproductive mimicry of bell-flowers (Campanula) by the red helleborine orchid (Cephalanthera rubra) invisible to the human eye, but not to the signal receivers, the solitary bees (Nilsson 1983).

Thus, the triadic concept of mimicry implies a kind of Uexküllian approach to nature by raising the threefold question, what resembles what to whom? It gives evidence that there are infinite possibilities of similarity because of the plurality of perceptual worlds of different organisms. The only remaining general criterion of mimicry is the one of similar perceptions in the cognitive world of the signal receivers: "Common to all examples of mimicry [...] is the deception of a signal receiver by the counterfeit signal, that carries a quite specific meaning for the receiver" (Wickler 1968: 241).

\section{The semiotic dynamics of mimicry systems}

Mimicry has been found in most of classes of higher animals and plants inhabiting many ecological communities on land, in the air, and the water. All channels of communication, optical, acoustical, chemical, and tactile ones, occur in mimicry systems. Furthermore, signals sent and received by participants differ according to the factor of noise and other distractions in the environment. To explain such high variability among mimicry systems it is not enough to consider mimicry systems only as static situation. They must rather be interpreted as dynamically changing and evolving systems.

The systemic dynamics of the triadic sign-process of mimicry, may be studied with profit according to a cyclical communication model (cf. Nöth 1990: 177, 178). Mimicry is the result of a long sequence of semioses taking place between mimics and models as senders and signal receivers. Feedback mechanisms may be assumed to account for the stability and heterogeneity of the mimicry systems.

Mimicry arises from a signal receiver's permanent cognitive confusion between objects (mimics, models) between which perceptual distinctions must be made. There is a mimicry system when a selec- 
tive feedback loop occurs: a compensatory system allows signal receivers, by means of natural reproduction or artificial recreation, create features for future generations. Thus, a mimicry system is not just an individual resemblance, but a continuous and dynamic process of creating similarities via regulation.

According to these premises, semiosis in mimicry systems is a kind of filtering system, filtering signs accordingly to receivers' response. In most semiotic systems operating in situations of cyclical communication, signs correctly recognized by a receiver are passed on to the next generation. The mimicry system is characterized by the reverse situation: mimetic signs not recognized correctly by the receiver are transmitted, recognized signs are inhibited by a semiotic "filter" on the way to their receiver. For the description of this fundamental difference between mimicry and other sign systems, I propose the term "reverse feedback": in normal situations of communicative feedback, the signs may be recognized correctly by the receiver and pass the filter of semiosis, carrying the message on to the next generation. In reverse feedback, signs succeed which are recognized incorrectly by the receiver.

As mimetic signs evolve via exclusion, there should be several possibilities for these signs to evolve in the perception of the sign receivers. Studies of the diversity in biological mimicry show that for mimics there are many possibilities not to be recognized (Mallet \& Gilbert 1995; Joron \& Mallet 1998). Furthermore, at least in some cases, these different possibilities of not being recognized are mutually conditioned, e.g., in satyric mimicry, where mimics combine similar appearance with different escape strategies, thus using unexpected behaviour to escape from the predator (Howse \& Allen 1994).

Two opposed feedback cycles are at work in mimicry systems: a reverse feedback cycle that determines the similarity of the mimic to the model and a normal feedback cycle that determines the further effectiveness of the receiver via learning and memory. As similarities of mimics with their models and the receivers' potential to recognize objects will develop simultaneously, mimics and models are always confused by the signal receiver, even if their actual properties change. As shown by computer modelling, the mutual conditioning between the participants of the mimicry system is the source of a great stability (Holmgren \& Enquist 1999).

Thus, the factors required for the evolution of a mimicry system are: similarity of objects in the perceptual world of the signal receiver, patterns of advantage and disadvantage, and feedback cycles, i.e., se- 
lective reproduction or recreation of participants of the mimicry system. The concurrence of these factors may happen anywhere and under many environmental circumstances, provided there is communication between organisms and a common perceptual world. Once that common structure of a mimicry system has developed, the system is able maintain itself through random changes of surrounding structures and contexts (e.g., influences of noise and channel properties).

Furthermore, if it is in the receiver's interest to distinguish between mimics and models, the signal receiver should also develop better cognitive and semiotic capabilities to recognize these deceptive resemblances. Thus, mimicry systems in the bio-semiosphere may also be seen as sources of the development of potential, vortex-like structures which are able to maintain themselves and transform the biological potential of developing into a semiotic one.

\section{Mimicry systems in the ecosemiotic frame}

Ecosemiotics, as first defined by Nöth (1996) and further specified by Kull (1998), is the semiotics of relationships between culture and nature. Thus, from the biosemiotic viewpoint ecosemiotics deals with Umwelt and Innenwelt of one species, Homo sapiens. Theoretically mimicry systems as phenomena of biosemiotics may occur in any organism, including humans. Potentially, humans can fulfil any of three roles of the triadic nature of a mimicry system, i.e., being a mimic, a model, or a signal receiver. According to Vane-Wright's theory of mimicry types there might also be conjunct mimicry systems in human culture. Humans have developed many deceptive strategies and devices based on imitation. A simple example is the production of inexpensive products by companies (mimic) imitating the production of high quality products (model) in order to deceive the customers (receiver). Another example of a human mimicry system is false money (mimic) imitating real money (model) to deceive traders (receiver).

It is also possible to find mimicry systems which connect humans with the rest of the nature and which have shaped our cultural consciousness and understanding of nature in general. An example of such a mimicry system are secondary crops like rye and flax (mimics) which have developed from weeds by mimicking man's first crop (model), which was wheat (cf. Pasteur 1982: 187). In this mimicry 
system, the signal receivers were first Neolithic humans and much later agricultural machines. Another case of ecosemiotic mimicry from prehistorical times is the ancient strategy of humans to get better hunting results by concealing themselves or by mimicking prey-species. Modern methods of concealment as a strategy in military action may be regarded as continuation of this mimicry system.

Contemporary examples of mimicry relations between culture and nature are plastic flowers (mimics) which resemble real ones (models) to ordinary people (signal receivers) or artificial animals invented as mimics of real pets for infants (more recently Tamagotchis, cf. Schmauks 2000).

Although ecosemiotic mimicry systems developed by humans have quite often some cultural connotations and values, making them thus also objects of cultural semiotics, the approach proposed here suggests that they may be a valuable source for further research in the eco- and biosemiotic frames. ${ }^{14}$

\section{References}

Atkinson, George F. 1888. New instances of protective resemblance in spiders. American Naturalist 22: 545-546.

Bates, Henry Walter 1862. Contributions to the insect fauna of the Amazon valley: Lepidoptera: Heliconidae. Transactions of the Linnean Society 23: 495566.

Blest, A. David 1957. The function of eyespot patterns in the Lepidoptera. Behaviour 11: 209-256.

Bowers, Deane M.; Brown, Irene L.; Wheye, Darryl 1985. Bird predation as a selective agent in a butterfly population. Evolution 39(1): 93-103.

Bowler, Peter J. 1983. The Eclipse of Darwinism: Anti-Darwinian Evolution Theories in the Decades around 1900. Baltimore: The John Hopkins University Press.

Brier, Søren 2001. Cybersemiotics and Umweltlehre. Semiotica 134(1/4).

Brower, Jane van Zandt 1960. Experimental studies of mimicry IV: The reactions of Starlings to different proportions of models and mimics. American Naturalist 94: 271-282.

Brower, Jane van Zandt; Brower, Lincoln Pierson 1962. Experimental studies of mimicry 6: The reaction of toads (Bufo terrestris) to honeybees (Apis mel-

${ }^{14}$ For contributions to this paper in personal discussions or correspondence I am grateful to K. Lagerspetz, V. Mikita, W. Nöth, I. Pilt, I. Puura, P. Torop, and A. Turovski. I express my especial gratitude to Kalevi Kull for his long-lasting guidance to the depths of biology and biosemiotics. 
lifera) and their dronefly mimics (Eristalis vinetorum). American Naturalist 96: 297-307.

Brower, Lincoln Pierson; Brower, Jane van Zandt 1964. Birds, butterflies and plant poisons: A study in ecological chemistry. Zoologica 49: 137-159.

Brower, Lincoln Pierson (ed.) 1988. Mimicry and the Evolutionary Process. Chicago: University of Chicago Press.

Burd, Martin 1994. Butterfly wing colour patterns and flying heights in the seasonally wet forest of Barro Colorado Island, Panama. Journal of Tropical Ecology 10(4): 601-610.

Cloudsley-Thompson, J. L. 1981. Comments on the nature of deception. Biological Journal of the Linnean Society 16: 11-14.

Damian, Raimond T. 1963. Molecular mimicry: Antigen sharing by parasite and its host and its consequences. American Naturalist 98: 129-149.

Darwin, Charles 1859. On the Origin of Species by Means of Natural Selection, or the Preservation of Favoured Races in the Struggle of Life. London: John Murray.

- 1874. The Descent of Man, and Selection in Relation to Sex [2nd ed.]. London: John Murray (1st ed. 1871).

Eimer, Theodor G. 1897. Orthogenesis der Schmetterlinge. Leipzig: Engelmann.

Finn, Frank 1897. Contributions to the theory of warning colorations and mimicry. No III. Experiments with a Tupaia and a Frog. Journal of the Asiatic Society of Bengal 66: 528-533.

Ford, Edmund Brisco 1989. Mimicry. In: Sebeok, T.A. (ed.), Encyclopedic Dictionary of Semiotics, Berlin: Mouton de Gruyter, 552-553.

Francé, Raoul Heinrich 1908. Das Leben der Pflanze. Stuttgart: Kosmos.

Gingerich, Philip Derstine 1975. Is the aardwolf a mimic of the hyaena? Nature 153(5488): 191-192.

Guthrie, Steward Elliott 1993. Faces in the Clouds: A New Theory of Religion. New York: Oxford University Press.

Heikertinger, Franz 1933. Kritisches zum Mimikryproblem: Über Schmetterlingsmimikry. In: 5th International Congress of Entomology. Paris, 119-130.

- 1954. Das Rätsel der Mimicry und seine Lösung. Jena: Gustav Fisher Verlag.

Holmgren, Noél. N. M.; Enquist, Magnus 1999. Dynamics of mimicry evolution. Biological Journal of the Linnean Society 66(2): 145.

Howse, P. E.; Allen, John A. 1994. Satyric mimicry: The evolution of apparent imperfection. Proceedings of Royal Society London B, 111-114.

Jackson, Robert R.; Wilcox, Stimson R. 1993. Spider flexibly chooses aggressive mimicry signals for different prey by trial and error. Behaviour 127(1-2): 2136.

Johnson, S. D. 1994. Evidence for Batesian mimicry in a butterfly-pollinated orchid. Biological Journal of the Linnean Society 53: 91-104.

Joron, Mathieu; Mallet, James L. B. 1998. Diversity in mimicry: Paradox or paradigm? Trends in Ecology and Evolution 13(11): 461-466.

Kull, Kalevi 1998. Semiotic ecology: Different natures in the semiosphere. Sign Systems Studies 26: 344-371. 
Lenoir, A.; Malosse, C.; Yamaoka, R. 1997. Chemical mimicry between parasitic ants of the genus Formicoxenus and their host Myrmica (Hymenoptera, Formicidae). Biochemical Systematics and Ecology 25: 379-389.

Malcolm, Edmunds 1987. Mimicry. In: The Oxford Companion to Animal Behaviour. Oxford: Oxford University Press, 387-389.

Malcolm, Stephen B. 1990. Mimicry: Status of a classical evolutional paradigm. Trends in Ecology and Evolution 5(2): 57-62.

Mallet, James; Gilbert, Lawrence E. Jr. 1995. Why are there so many mimicry rings? Correlation between habitat, behavior and mimicry in Heliconus butterflies. Biological Journal of the Linnean Society 55: 159-180.

Maran, Timo 1999. A note on the semiotics of biological mimicry. Sign Systems Studies 27: 139-146.

- 2000. Bioloogiliste mimikrinähtuste semiootika. [Semiotics of biological mimicry] MA thesis. Tartu: Tartu University, Department of Semiotics.

Morell, Virginia 1996. Staring species with third parties and sex wars. Science 273(5281): 1499-1503.

Müller, Fritz von 1878. Über die Vortheile der Mimikri bei Schmetterlingen. Zoologischer Anzeiger 1: 54-55.

Nilsson, Anders L. 1983. Mimesis of bellflower (Campanula) by the red helleborine orchid Cephalanthera rubra. Nature 305(5937): 799-800.

Nöth, Winfried 1990. Handbook of Semiotics. Bloomington: Indiana University Press.

- 1996. Ökosemiotik. Zeitschrift für Semiotik 18(1): 7-18.

- 1998. Ecosemiotics. Sign Systems Studies 26: 332-343.

- 2000. Handbuch der Semiotik. 2. Aufl. Stuttgart: Metzler.

Pasteur, George 1982. A classificatory review of mimicry systems. Annual Review of Ecological Systems 13: 169-99.

Peckham, E. G. 1889. Protective resemblances of spiders. Occasional Papers of the Natural History Society of Wisconsin 1: 61-113.

Poulton, Edward B. 1887. The experimental proof of the protective value of color and markings in insects in reference to their vertebrate enemies. Proceedings of the Zoological Society of London 16: 191-274.

- 1890. The Colours of Animals, Their Meaning and Use. New York: Appleton.

Raguso, Robert A.; Roy, Barbara A. 1998. 'Floral' scent production by Puccinia rust fungi that mimic flowers. Molecular Ecology 7(9): 1127.

Robinson, Michael H. 1981. A stick is a stick and not worth eating: On the definition of mimicry. Biological Journal of the Linnean Society 16: 15-20.

Roy, Barbara A.; Raguso, Robert A. 1997. Olfactory versus visual cues in a floral mimicry system. Oecologia 109(3): 414-426.

Roy, Barbara A.; Widmer, Alex 1999. Floral mimicry: A fascinating yet poorly understood phenomenon. Trends in Ecology and Evolution 4(8): 325-330.

Ruiter, Leendert de 1952. Some experiments on the camouflage of stick-caterpillars. Behaviour, 4: 222-232.

- 1958. Some remarks on problems of the ecology and evolution of mimicry. Archives Neerlandaises de Zoologie 13: 351-68.

Schmauks, Dagmar 2000. Teddy bears, Tamagotchis, transgenic mise: A semiotic typology of artificial animals. Sign Systems Studies 28: 309-325. 
Sebeok, Thomas A. 1979. The Sign and its Masters. Lanham: University Press of America.

— 1986 "Talking" with animals: Zoosemiotics explained. In: Deely, J.; Williams, B.; Kruse, F.E. (eds.), Frontiers in Semiotics. Bloomington: Indiana Univ. Press, 76-82.

- 1990. Essays in Zoosemiotics. Toronto: University of Toronto.

Shelford, R. 1902. Observations on some mimetic insects and spiders from Borneo and Singapore. Proceedings of Zoological Society. London, 240-274.

- 1912. Mimicry amongst the Blattidae; with a revision of the genus Prosoplecta Sauss. and the description of a new genus. Proceedings of Zoological Society, London, 358-376.

Thayer, Gerald H. 1909. Concealing-coloration in the Animal Kingdom: An Exposition of the Laws of Disguise through Color and Pattern. New York: Macmillan.

Tinbergen, Niko 1960. The natural control of insects in pine woods. Archives Neerlandaises de Zoologie 13: 265-343.

Turner, John R. G.; Speed, M. P. 1996. Learning and memory in mimicry. 1. Simulations of laboratory experiments. Philosophical Transactions of the Royal Society of London - Series B: Biological Sciences 351(1134): 11571170.

Uesugi, K. 1996. The adaptive significance of Batesian mimicry in the swallowtail butterfly, Papilio polytes (Insecta, Papilionidae): Associative learning in a predator. Ethology 102(9): 762-775.

Uexküll, Jakob von 1957. A scroll through the world of animals and men: A picture book of invisible worlds. In: Schiller, Claire H. (ed.), Instinctive behavior: The development of a modern concept. New York: International Universities Press, 5-80.

Vane-Wright, Richard I. 1976. A unified classification of mimetic resemblances. Biological Journal of the Linnean Society 8: 25-56.

- 1980. On the definition of mimicry. Biological Journal of the Linnean Society 13: $1-6$.

Voigt, Vilmos 1986. Early forms of iconicity in ethnic and folk art. In: Bouissac, P.; Herzfeld, M.; Posner, R. (eds.), Iconicity: Essays on the Nature of Culture. Tübingen: Stauffenburg, 385-408.

Wallace, Alfred Russel 1870. Mimicry, and other protective resemblance among animals. In: Alfred Russel Wallace. Contributions to the Theory of Natural Selections: A Series of Essays. London: Macmillan, 45-129.

Wickler, Wolfgang 1965. Mimicry and the evolution of animal communication. Nature 208: 519-21.

- 1968. Mimicry in plants and animals. Trans. R. D. Martin. London: George Weidenfeld \& Nicolson.

Wiens, Derbert 1978. Mimicry in plants. Evolutionary Biology 11: 364-403.

Winhard W. 1996. Convergent development of color patterns in butterflies: Field studies in Asia, Africa and South America. Spixiana Supplement 0(21): 1192. 


\section{Мимикрия: к семиотическому пониманию природы}

Мимикрия оставалась в центре внимания биологии начиная с возникновения теории эволюции Дарвина. Но по своему характеру мимикрия является знаковым процессом, а поэтому и стремление биологии понять явления мимикрии отличалось имплицитной семиотичностью. В данной статье рассматриваются различные теории, начиная с работ Генри У. Бейтса, для демонстрации того, как первичное понимание мимикрии в качестве воспринимаемых подобий развилось в теорию о мимикрии как структурах коммуникации. Очерчивают концепцию мимикрии, которая подчеркивает динамические свойства этого явления и прослеживают явления мимикрии в рамках экосемиотической парадигмы.

\section{Mimikri: looduse semiootilise mõistmise poole}

Mimikri on olnud bioloogia tähelepanukeskmes alates Darwini evolutsiooniteooria tekkest. Ent oma loomult on mimikri siiski märgiprotsess ja nii on ka bioloogia püüd mõista mimikrinähtusi olnud varjatult semiootiline. Käesolevas artiklis vaadeldakse erinevaid teooriaid alates Henry W. Bates'i töödest näitamaks, kuidas algne arusaam mimikrist kui tajutavatest sarnasustest on arenenud teooriaks mimikrist kui kommunikatsiooni struktuuridest. Seejärel esitatakse mimikrikontseptsioon, mis rõhutab nähtuse dünaamilisi omadusi ning viimaks vaadeldakse mimikrinähtusi ökosemiootika paradigma raames. 